\title{
Prognostic significance of the sequential detection of circulating melanoma cells by RT-PCR in high-risk melanoma patients receiving adjuvant interferon
}

\author{
H Gogas*,', G Kefala', D Bafaloukos², K Frangia², A Polyzos', D Pectasides², D Tsoutsos², P Panagiotou², \\ $J$ loannovich ${ }^{2}$ and $D$ Loukopoulos'
}

'Research Laboratory of Ist Department of Medicine, University of Athens; Aghiou Thoma 17, Goudi, Athens II 527, Greece; ${ }^{2}$ Hellenic Cooperative Oncology Group (HeCOG), Data office, Laskaridou I, Athens II 524, Greece

The purpose of this study was to address the prognostic significance of circulating melanoma cells by reverse transcriptasepolymerase chain reaction in the peripheral blood of stage IIB and III melanoma patients on high-dose adjuvant interferon at multiple sequential time points from initiation of treatment. Tyrosinase mRNA in peripheral blood from these patients was assayed by reverse transcriptase polymerase chain reaction prior to initiation of adjuvant interferon, at completion of I month of intravenous interferon and at 3 monthly intervals until progression. Four hundred and eighteen blood samples from 60 melanoma patients were analysed. The median follow-up time calculated from the time of inclusion in the study was 23 months (range 2-38 months). Tyrosinase mRNA in blood was detected in 42 (70\%) of 60 patients: 16 (76\%) of 21 stage IIB patients and 26 (66\%) of 39 stage III patients. The presence of tyrosinase mRNA in blood was correlated with a shorter disease-free survival $(P: 0.03)$ and in multivariante analysis was an indepent prognostic factor for relapse. Patients who seroconverted to a negative reverse-transcriptase-polymerase chain reaction after induction treatment had a significantly lower probability of recurrence. The presence of circulating melanoma cells is a marker of a high relapse risk and shorter disease-free survival whether detected postoperatively or during follow-up. Tyrosinase mRNA amplification by reverse-transcriptasepolymerase chain reaction may be a useful tool for monitoring the efficacy of adjuvant treatment in stage IIB and III melanoma patients.

British Journal of Cancer (2002) 87, 181 - 186. doi:10.1038/sj.bjc.6600419 www.bjcancer.com

(c) 2002 Cancer Research UK

Keywords: tyrosinase mRNA; interferon; melanoma; RT-PCR

For detecting tumour cells in melanoma patients reverse transcription-polymerase chain reaction (RT-PCR) has been used to identify tyrosinase, a key enzyme in melanin biosynthesis, in the circulation of patients with disseminated disease (Smith et al, 1991). The tyrosinase gene is actively expressed only in melanocytes and melanoma cells (Kwon et al, 1987) and as melanocytes cannot be detected in the circulation, the detection of tyrosinase RNA indicates the presence of melanoma cells.

The relationship between circulating tumour cells and the development of secondary disease is not fully understood. The presence of such cells in peripheral blood samples from early stages melanoma could indicate a dissemination of the tumour cells, and thus a high risk of metastasis. If confirmed circulating melanoma cells could represent a new prognostic marker with which to predict clinical behaviour, assess tumour progression, and improve patient management.

However, different research groups reported conflicting results on the sensitivity and clinical value of tyrosinase RT-PCR (Foss et al, 1995; Stevens et al, 1996; Jung et al, 1997; Glaser et al,

\footnotetext{
* Correspondence: H Gogas, Lecturer in Medical Oncology, Ist Department of Medicine, University of Athens, P.O. BOX 14120, Athens I 1510, Greece; E-mail: hgogas@hol.gr
}

Received 3 December 200 I; revised 8 April 2002; accepted 29 April 2002
1997). In patients with localised disease (stages I and II) the percentage of blood samples that test positive for tyrosinase varies greatly ranging from 0 (Kunter et al, 1996) to 45\% (Reinhold et al, 1997). Blood samples from untreated patients with advanced disease show remarkable differences in tyrosinase-positive rates, which range from 0 to $44 \%$ (Battayani et al, 1995) for stage III patients and from 13\% (Pittman et al, 1996) to 100\% for stage IV patients (Brossart et al, 1993). Some groups have found that RT-PCR for tyrosinase maybe a prognostic marker in both early and late stages of disease. In one study PCR detection of circulating melanocytes was considered as a marker for rapid postoperative relapse after node dissection in patients with melanoma and regional node metastases, for short-term relapse in high-risk disease-free patients and for rapid and severe progression in patients with distant metastases (Battayani et al, 1995).

Although most of the studies have been focused on the detection of circulating melanoma cells at the time of initial diagnosis they can also be detected in blood months or years after primary tumour diagnosis (Curry et al, 1998).

However the biological and clinical implications that may be associated with the presence of circulating malignant cells during the follow-up of melanoma patients are not clear. To address the prognostic implications of the presence of late circulating melanoma cells, we decided to investigate the presence of tyrosinase mRNA by RT-PCR in the peripheral blood of stage IIB and III 
melanoma patients on high-dose adjuvant interferon a- $2 \beta$ at multiple sequential time points from initiation of treatment.

\section{MATERIALS AND METHODS}

\section{Patients}

Patients with a histologically documented diagnosis of cutaneous melanoma, stage IIB or III according to the American Joint Committee on Cancer (AJCC) guidelines were included in the study. Stage was defined on a pathological basis. Patients underwent sentinel node dissection. Any patient with a positive SLN was required to undergo a complete lymphadenectomy. All patients were initiated on high-dose inteferon according to Hellenic Cooperative Oncology Group protocol (Gogas et al, 2000) 2 months after initial surgery, or 1.5 months after therapeutic lymph node dissection for regional lymph node recurrence. Oral informed consent was obtained from each patient. Blood for tyrosinase RT-PCR was drawn at the same time that blood extraction was performed for previous established follow-up: the first $20 \mathrm{ml}$ of blood collected were used for standard biochemistry and cell blood counts, and the following $15 \mathrm{ml}$ were used for RT-PCR studies. Blood samples were obtained prior to induction treatment, at completion of 1 month intravenous interferon, and at 3 monthly intervals until progression. The clinical outcome of patients was prospectively followed. Clinical staging consisted of medical history, physical exam, cell blood count, blood biochemistry at 3 monthly intervals, chest X-ray and liver ultrasound at 6 monthly intervals. Other complimentary exams were performed if they were clinically indicated. Patients with a positive RT-PCR were not subjected to a more intensive follow-up than were those with a negative RT-PCR and no clinical decisions were made based on the results of the RT-PCR assay. Negative controls were healthy subjects and patients with other malignancies.

\section{Samples - RNA extraction}

Twelve to $15 \mathrm{ml}$ of blood were collected in EDTA anticoagulant from each patient. The mononuclear cell fraction of peripheral blood was isolated by ficoll gradient centrifugation (Boyum, 1968). Total RNA was isolated from the mononuclear cell fraction by guanidium thiocyanate extraction (Chomczynski and Sacchi, 1987). The extracted RNA was dissolved in ddH20. Integrity was evaluated by assesing the $18 \mathrm{~S}$ and $28 \mathrm{~S}$ ribosomal RNA bands in $2 \%$ ethidium-bromide-stained agarose gel. The amount of RNA was calculated by spectrophotometric analysis.

\section{Complementary DNA synthesis}

For the complementary DNA (cDNA) synthesis $1 \mu \mathrm{g}$ of RNA was incubated for $5 \mathrm{~min}$ at $65^{\circ} \mathrm{C}$ with $3 \mu \mathrm{g}$ Random Primer oligonucleotides (Gibco-BRL), in a total volume of $13 \mu \mathrm{l}$. One $\mathrm{mM}$ of each deoxynucleotide triphospate (dNTP) (New England Biolabs), $1 \times$ First Strand Buffer and $200 \mathrm{U}$ Moloney Murine Leukemia Virus Reverse Transcriptase (M-MLV RT) (Gibco BRL), were added to a final volume of $20 \mu \mathrm{l}$. cDNA synthesis was performed for $1 \mathrm{~h}$ at $37^{\circ} \mathrm{C}$, followed by enzyme denaturation at $95^{\circ} \mathrm{C}$ for 2 min.

The Retinoic Acid Receptor a (RARa) gene was used as an internal control for assessing the quality of the cDNA. Effective amplification using the primers RaR6 and RaR8 confirmed the quality of the samples.

\section{PCR method}

Ten $\mu \mathrm{l}$ of the previously obtained cDNA sample were amplified in the first PCR round using 100 pmol of each primer HTYR1 (sense:
TTG, GCA, GAT, TGT, CTG, TAG, CC) and HTYR2 (antisense: AGG, CAT, TGT, GCA, TGC, TGC, TT) (Smith et al, 1991).

The reaction mixture also contained $0.2 \mathrm{~mm}$ of each dNTP, $1 \times$ PCR buffer, $2 \mathrm{mM} \mathrm{MgCl} 2$ and $2 \mathrm{U}$ Taq DNA Polymerase (Gibco BRL) in a final volume of $50 \mu \mathrm{l}$.

The PCR began with one cycle of $5 \mathrm{~min}$ at $94^{\circ} \mathrm{C}$ for template denaturation, followed by 30 cycles of $1 \mathrm{~min}$ denaturation at $94^{\circ} \mathrm{C}, 1 \mathrm{~min}$ at $55^{\circ} \mathrm{C}$ for primer annealing and $1 \mathrm{~min}$ for polymerase extension at $72^{\circ} \mathrm{C}$. The reaction was terminated with a $10 \mathrm{~min}$ extension at $72^{\circ} \mathrm{C}$. Five $\mu \mathrm{l}$ of a $1: 100$ dilution of the first-round PKR product were reamplified using the nested primers HTYR3 (sense: GTC, TTT, ATG, CAA, TGG, AAC, GC) and HTYR4 (antisense GCT, ATC, CCA, GTA, AGT, GGA, CT) (1) in a $25 \mu$ final volume, for a further round of 30 cycles under the same conditions as the first PCR round.

The outer primers amplify a PCR, product of 284 base pairs, while the nested primers amplify a fragment of 207 base pairs. The PCR products were visualised in ethidium bromide-stained $3 \%$ agarose gel.

To determine the sensitivity of the assay serial dilutions of $10^{6}$ to 1 SK-Mel 28 cells in $10^{7}$ normal mononuclated peripheral blood cells, were prepared. RT-PCR was performed using $1 \mu \mathrm{g}$ of total RNA from each dilution. The sensitivity of the method was high enough to detect 10 SK-Mel 28 cells in $10^{7}$ normal cells. Southern blot was performed to confirm that our RT-PCR amplified products were indeed from tyrosinase.

\section{Statistical analysis}

Relapse free survival was calculated from the initiation of treatment to the date relapse of the disease (RFS) was firstly documented and overall survival (OS) from initiation of treatment to the date of death or last contact. All patients without the corresponding event by 30/9/00 were considered censored. Sensitivity was calculated as the proportion of relapsed patients with positive RT-PCR. Specificity as the proportion of non-relapsed patients with negative RTPCR. Positive predicted value as the proportion of positive RTPCR patients with relapse. Negative predicted value as the proportion of negative RT-PCR patients without being relapsed.

The $\chi^{2}$ test were used to test the association between RT-PCR status and stage, Breslow, Clark, ulceration, regression, lymph node status, primary tumour location, sex, age. The Kaplan-Meier method was used to calculate RFS and OS curves, while the logrank test was used to compare time to event distributions. Multivariate analysis were performed with Cox proportional hazard models in order to indicate independent prognostic factors for survival and relapse-free survival. A backward selection procedure identified the subclass of significant variables among the following: stage (IIB vs III), Breslow (0-2 vs 2.1-4>4), Clark (II-III vs IV $v s \mathrm{~V})$, ulceration (No vs Yes), regression (No vs Yes), lymph node status (No $v s$ Yes) primary tumour location, sex (male $v s$ female), age $(<52$ vs 52). The significant factors were kept in the model if the maximum likelihood ration criterion had a $P$-value below 0.10 . All reported $P$-values are two-sided.

Calculations were made using each patient. A negative patient is a patient whom no positive result has ever been obtained and a positive patient, is a patient in whom at least one positive test has been obtained. As all patients with positive sentinel lymphnode had undergone lymphadenectomy, no nodal relapses were seen in our study population and relapses are distant metastasis.

\section{RESULTS}

\section{Patients}

Four hundred and eighteen blood samples from 60 melanoma patients were tested for tyrosinase mRNA in blood by RT-PCR. The median number of RT - PCR tests per patient was seven (range 
2 to 13). Blood from eight controls (four patients with breast cancer and four patients with colon cancer) was also examined. Patient's characteristics are described in Table 1. The patients were followed for a median time (calculated from the inclusion in the study) of 23 months (range 2, -38+months, 95\% CI 17.4-28.6).

\section{RT - PCR status and relapses}

RNA samples that showed the $28 \mathrm{~S}$ and $18 \mathrm{~S}$ ribosomal band were considered eligible for the study (Figure 1A). Samples showing a band of $207 \mathrm{bp}$ after a second round of amplification with nested primers are considered positive (Figure 1B). Using the same RT PCR technique no false-positive results among 16 samples from non melanoma control patients (eight healthy subjects and eight patients with other cancers). Hence, no illegitimate transcription in the haematopoietic cells was observed among the non melanoma controls with the experimental conditions used.

Here $105(25 \%)$ of 418 blood samples were positive for tyrosinase. Circulating melanoma cells were detected in 42 of 60 patients. There was no correlation between RT-PCR status and age, sex, Breslow, Clark, ulceration, regression, lymph node involvement and stage. Prior to initiation of induction treatment with intravenous interferon 30 patients had negative RT-PCR, and 30 had positive. After completion of 1 month of induction treatment 16 patients were tested with a negative RT-PCR and 14 continued to test positive. In the group of patients who initially had a negative RT-PCR result, 21 had a second negative result and nine seroconverted, to a positive result, after 4 weeks of intravenous

Table I Patients characteristics

\begin{tabular}{|c|c|}
\hline & No. of patients \\
\hline Total no. & 60 \\
\hline No. of males $/$ no. of females & $34 / 26$ \\
\hline Median age (yrs) & 52 (range $27-78)$ \\
\hline \multicolumn{2}{|l|}{ Stage (AJCC) } \\
\hline$\| B$ & 21 \\
\hline III & 39 \\
\hline \multicolumn{2}{|l|}{ Histology } \\
\hline Superficial spreading & 21 \\
\hline Nodular & 26 \\
\hline Acral letiginous & 4 \\
\hline Other & 7 \\
\hline MLM & 2 \\
\hline \multicolumn{2}{|l|}{ Primary site } \\
\hline Lower extremities & 22 \\
\hline Upper extremities & 8 \\
\hline Trunk & 18 \\
\hline Head and neck & 8 \\
\hline Mucosal & 2 \\
\hline Unknown & 2 \\
\hline \multicolumn{2}{|l|}{ Clark } \\
\hline$\|-\| \|$ & 9 \\
\hline IV & 37 \\
\hline $\mathrm{V}$ & 6 \\
\hline Unknown & 8 \\
\hline \multicolumn{2}{|l|}{ Breslow } \\
\hline $0-2$ & 7 \\
\hline $2.1-4$ & 15 \\
\hline$>4$ & 35 \\
\hline Unknown & 3 \\
\hline \multicolumn{2}{|l|}{ Regression } \\
\hline No & 31 \\
\hline Yes & 12 \\
\hline Unknown & 17 \\
\hline \multicolumn{2}{|l|}{ Ulceration } \\
\hline No & 15 \\
\hline Yes & 31 \\
\hline Unknown & 14 \\
\hline
\end{tabular}

\section{A}
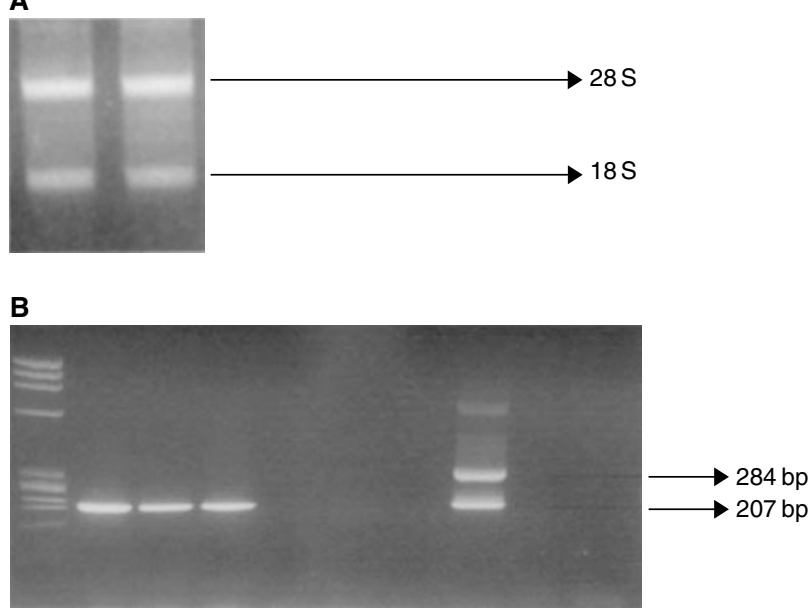

Figure I (A) $28 \mathrm{~S}$ and $18 \mathrm{~S}$ rRNA bands. Total RNA extraction as visualised in ethidium bromide stained $2 \%$ agarose gel. (B) Ethidium bromide-stained gel visualisation of RT-PCR products showing a $207 \mathrm{bp}$ band in the positive samples. Lane I. Molecular Weight Marker ( $\Phi \times 174$ RF DNA Haelll Digest). Lanes $2-4$. Positive samples (three melanoma patients). Lanes $5-7$. Negative samples (three melanoma patients). Lane 8. Positive control (SK-mel 28 cell line). Lane 9. Negative control (healthy donor). Lane 10. Negative control (sample without cDNA).

high-dose interferon. Eighteen patients had sequential negative RT - PCRs and 42 patients had one or more positive blood samples for tyrosinase. With a median follow-up of 23 months 29 patients have recurred and 13 have died from melanoma dissemination. One patient has died, remaining disease-free. Eighteen patients had a positive RT - PCR at initiation of adjuvant treatment, eight tested positive during follow-up and finally three had sequential negative RT-PCRs even at relapse. The sites of relapse for these RT-RCR negative patients were subcutaneous tissue (1), lymph nodes (2). The median interval between the detection of a positive RT - PCR result and the diagnosis of clinical relapse was 21 months (range 1-36 months, 95\% CI 11.7-20.3). In the group of patients with no evidence of disease, 15 had multiple negative RT-PCRs, nine had a positive sample prior to induction therapy and negative results during treatment and further follow-up, two had initially two positive RT-PCRs (one prior to induction therapy and at completion of intravenous interferon) and negative samples during maintenance treatment and further follow-up, and finally five patients had more than one positive sample during follow-up (Table 2).

The RT-PCR positivity by tyrosinase mRNA in blood during follow-up of patients with melanoma significantly correlated with shorter disease-free survival $(P: 0.029)$. The median disease-free survival was 21 months (95\% CI 12.7-29.3) for the RT-PCR positive group. The median disease-free survival was not reached for the group of patients testing negative for tyrosinase in blood (Figure 2). Median overall-survival was not reached for either group of patients (Figure 3 ).

In univariante analysis for relapse free survival only RT-PCR status was correlated with relapse $(P: 0.03)$ (Table 3$)$. In univariante analysis for survival no variable was found to be correlated with RT-PCR status (Table 4). In multivariante analysis (Cox regression analysis) RT-PCR status was the only independent prognostic factor for relapse $(\beta=1.3,95 \% \quad \mathrm{CI}=0.1-2.5, \quad P$ value $=0.03)$. No independent prognostic factor was found for overall survival. Multivariate analysis was performed without the factors ulceration and regression because of large numbers of unknown values and the results were exactly the same as these mentioned above. 
Table 2 RT-PCR status and relapses

Sequential negative

Initial positive and sequential negative

Positive RT - PCR anytime

out of 18

2 out of 11

24 out of 31

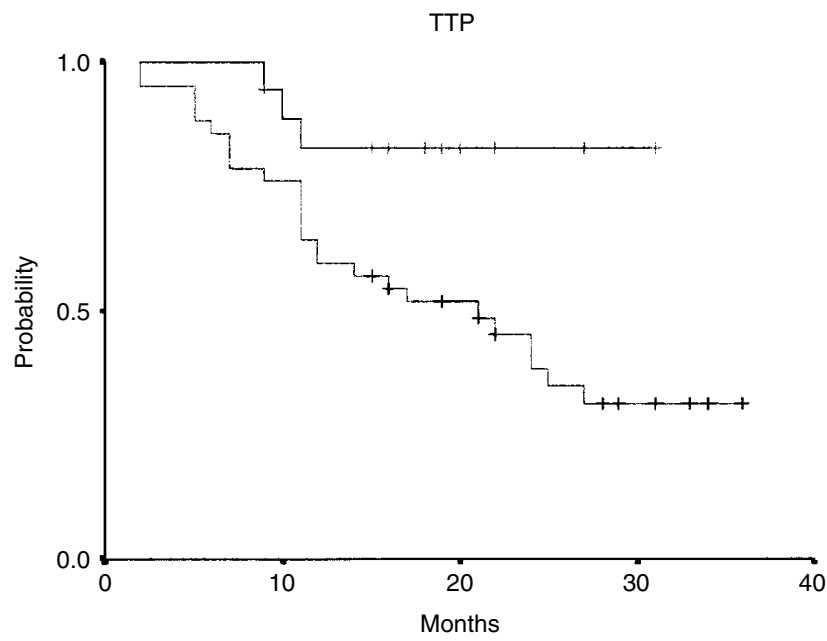

Figure 2 RT-PCR results and relapse-free survival in stage IIB and III melanoma patient calculated by the Kaplan-Meier method.

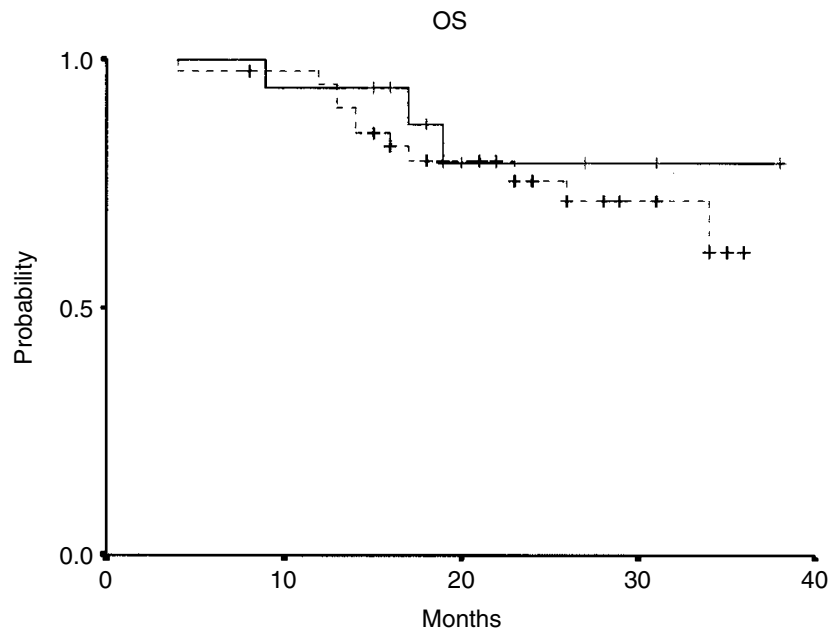

Figure 3 RT - PCR results and overall survival in stage IIB and III melanoma patients calculated by the Kaplan-Meier method.

The sensitivity (probability that a patient who tests positive has recurrent disease) was $89.66 \%(95 \% \mathrm{CI}=72-98 \%)$ and the specificity (probability that a patient who tests negative remained diseasefree) was $48.39 \%(95 \% \mathrm{CI}=30-67 \%)$. The positive predictive value was $61.90 \%(95 \% \mathrm{CI}=46-76 \%)$ and the negative predictive value was $83.33 \%(95 \% \mathrm{CI}=59-96 \%)$.

There was a statistically significant difference in the proportion of patients remaining disease-free and patients with negative (15 out of $18=83 \%$ ) and those with positive RT - PCR (16 out of $42=38 \%)(P=0.002)$. There was evidence that the proportion ( 9 out of $11=82 \%$ ) of seroconverted patients (patients who had a positive RT-PCR prior to induction therapy and negative RT PCRs during treatment and further follow-up) remaining diseasefree was statistically significantly higher than that $(7$ out of
$31=23 \%)$ of patients being positive $(P=0.001)$. Furthermore, there was not any evidence that the proportion of seroconverted patients remaining disease-free was statistically significantly higher than that ( 15 out of $18=83 \%)$ of patients being negative $(P=0.92)$.

\section{DISCUSSION}

Conflicting results have been obtained by various research groups using tyrosinase reverse transcription-polymerase chain reaction (RT-PCR) for detecting micrometastases in the blood of melanoma patients, with positive results ranging from 0 to $100 \%$ in disseminated melanoma. Methological differences in the processing of blood samples may in part account for these discrepancies. The prognostic significance of the detection of circulating melanoma cells by RT - PCR has been evaluated in several studies. In high-risk but apparently disease-free patients, the risk of relapse within the next 6 months was 3.8 times higher after a positive test result, than after negative PCR test ( $P: 0.002)$, and in patients with distant metastases after a positive PCR, rapid progression was four times more likely than slow progression or stable disease (Battayani et al, 1995). In another study patients with a positive PCR showed a 2.4-fold increased risk for relapse compared with PCR-negative patients (Schittek et al, 1999). The Melanoma Cooperative Group performed RT-PCR using tyrosinase, p 97, MUC 18, and MelanA/MART1 as gene markers in 235 patients with either localised or metastatic melanoma. Univariante analysis showed a significant correlation between risk of recurrence (evaluated in stage I, II and III patients and increasing number of PCR-positive markers $(P$ : $0.0002)$. Logistic regression multivariante analysis indicated that each single marker (except tyrosinase) and more especially, the presence of PCR-positive markers remained a statistically independent prognostic factor for tumour progression (Pialmieri et al, 1999). Finally in one study conducted in long-term clinically disease-free melanoma patients, regardless of their initial clinical stage, the presence of late circulating melanoma cells was significantly associated with a subsequent high risk of relapse and death (Mellado et al, 1999).

Here we specifically studied high-risk melanoma patients to assess the clinical significance of the sequential detection of circulating melanoma cells. The first finding from our data was that one or more positive tests for tyrosinase mRNA in blood during longterm follow-up of patients with melanoma was significantly correlated with a higher risk of relapse, shown both in univariante and multivariante analysis but not a higher risk of death from melanoma dissemination as found in other studies (Mellado et al, 1999). Maybe longer follow-up is warranted as median overall survival has not been reached by either tyrosinase positive or negative group. In another study (Curry et al, 1998) where blood samples from 276 melanoma patients were tested for tyrosinase and MART-1 at multiple sequential time points for at least 2 years after surgery, a low incidence of RT - PCR positivity was observed even up to 2 years after surgery. This occurred both in patients who had been continuously positive and in patients who had developed positive results after several negative results. Given the short follow-up of the patients, the authors could not assess, the prognostic significance of their late RT-PCR positive results and consequently could not exclude that these were false positive results. However the poor prognosis observed in our group of patients with a positive RT-PCR presented here suggest that these positivities are due to the presence of melanoma cells in the circulation in disease-free patients rather than those false-positive tests. This is also supported by the worst prognosis reported in other studies evaluating the role of the late circulating melanoma cells in long-term disease-free patients (Mellado et al, 1999).

Only three out of 18 patients with sequential negative RT - PCRs recurred $(16.6 \%)$, a difference which was statistically significant. Two out of 11 patients who tested positive prior to induction therapy and subsequently had negative RT-PCRs during treatment 
Table 3 Univariate analysis for relapse free survival

\begin{tabular}{|c|c|c|c|c|}
\hline & Events/Number & Median & $95 \% \mathrm{Cl}$ & $P$-value \\
\hline \multicolumn{5}{|l|}{$R T-P C R$} \\
\hline Negative & 3 out of 18 & NRY & N.E. & \\
\hline Positive & 26 out of 42 & 21 & $12.7-29.3$ & 0.03 \\
\hline \multicolumn{5}{|l|}{ Age } \\
\hline$<52$ & 14 out of 30 & 27 & $17.3-36.7$ & 0.57 \\
\hline$\geqslant 52$ & 16 out of 30 & 24 & $13.4-34.6$ & \\
\hline \multicolumn{5}{|l|}{ Sex } \\
\hline Male & 17 out of 34 & 22 & N.E. & 0.67 \\
\hline Female & 13 out of 26 & 24 & $19.6-28.4$ & \\
\hline \multicolumn{5}{|l|}{ Breslow } \\
\hline $0-2$ & 4 out of 7 & 24 & $5-43$ & \\
\hline $2.1-4$ & 9 out of 15 & 22 & $|4|-29.9$. & 0.87 \\
\hline$>4$ & 16 out of 35 & NRY & N.E. & \\
\hline \multicolumn{5}{|l|}{ Clark } \\
\hline$\|-\|||$ & 6 out of 9 & 12 & $3.2-20.8$ & \\
\hline IV & 18 out of 37 & 24 & $20-28$ & 0.09 \\
\hline V & 2 out of 6 & NRY & N.E. & \\
\hline \multicolumn{5}{|l|}{ Ulceration } \\
\hline No & 6 out of 15 & NRY & N.E. & 0.32 \\
\hline Yes & 16 out of 31 & 22 & $17.6-26.4$ & \\
\hline \multicolumn{5}{|l|}{ Regression } \\
\hline No & 15 out of 31 & 24 & $18.5-29.5$ & 0.20 \\
\hline Yes & 4 out of 12 & NRY & N.E. & \\
\hline \multicolumn{5}{|c|}{ Lymphnode involvement } \\
\hline No & 10 out of 21 & 24 & N.E. & 0.79 \\
\hline Yes & 20 out of 39 & 24 & $19.3-28.7$ & \\
\hline \multicolumn{5}{|l|}{ Stage } \\
\hline$\| B$ & 10 out of 21 & 24 & N.E. & 0.79 \\
\hline III & 20 out of 39 & 24 & $19.3-28.7$ & \\
\hline
\end{tabular}

and further follow-up, recurred which was again statistically different.

On the basis of this observation, it is reasonable to speculate that the late circulating melanoma cells detected in our patients can be shed from secondary organs. If this were true then the presence of circulating malignant cells in the setting of high-risk melanoma patients would be a marker of the existence of micrometastatic disease.

Patients who seroconverted to a negative RT - PCR result after induction treatment with intravenous interferon, had a significantly lower probability of recurrence. Even though, this is not a randomised study, and there were no untreated patients, and one could speculate that the conversion was a consequence of greater time after surgery, the surgery in this case either dislodging tumour cells or removing the source of tumour cells, the lower probability of recurrence strongly argues that the reversion was a consequence of interferon therapy. These results cannot be extrapolated to the general stage II and III population as IFN may have interfered with the results.

A negative RT - PCR result did not exclude tumour progression, as patients with sequential negative RT-PCRs developed metastases. Reasons proposed by other investigators might be that (i)

\section{REFERENCES}

Battayani Z, Grob JJ, Xerri L, Noe C, Zarour H, Houvaeneghel G, Delpero JR, Birmbaum D, Hassoun J, Bonerandi JJ (1995) PCR detection of circulating melanocytes as a prognostic marker in patiens with melanoma. Arch Dermatol 131: 443-447

Boyum A (1968) Separation of leucocytes from blood and bone marrow. Scand Clin Invest 21: $51-55$

Brossart P, Keiholz U, Willhauck M, Scheibenbogen C, Mohler T, Hunstein W (1993) Hematogenous spread of malignant melanoma cells in different stages of disease. J Invest Dermatol 101: 887-889
Table 4 Univariate analysis for overall survival

\begin{tabular}{|c|c|c|c|c|}
\hline & Events/Number & Median & $95 \% \mathrm{Cl}$ & $P$-value \\
\hline \multicolumn{5}{|l|}{$\mathrm{RT}-\mathrm{PCR}$} \\
\hline Negative & 3 out of 18 & NRY & N.E. & \multirow[t]{2}{*}{0.61} \\
\hline Positive & II out of 42 & NRY & N.E. & \\
\hline \multicolumn{5}{|l|}{ Age } \\
\hline$<52$ & 7 out of 30 & NRY & N.E. & \multirow[t]{2}{*}{0.84} \\
\hline$\geqslant 52$ & 7 out of 30 & NRY & N.E. & \\
\hline \multicolumn{5}{|l|}{ Sex } \\
\hline Male & 4 out of 26 & NRY & N.E. & \multirow[t]{2}{*}{0.19} \\
\hline Female & 10 out of 34 & NRY & N.E. & \\
\hline \multicolumn{5}{|l|}{ Breslow } \\
\hline $0-2$ & I out of 7 & NRY & N.E. & \multirow{3}{*}{0.59} \\
\hline $2.1-4$ & 3 out of 15 & NRY & N.E. & \\
\hline$>4$ & 10 out of 35 & 34 & N.E. & \\
\hline \multicolumn{5}{|l|}{ Clark } \\
\hline$\|-\| \mid$ & I out of 9 & NRY & N.E. & \multirow{3}{*}{0.55} \\
\hline IV & 10 out of 37 & NRY & N.E. & \\
\hline$\vee$ & I out of 6 & NRY & N.E. & \\
\hline \multicolumn{5}{|l|}{ Ulceration } \\
\hline No & 3 out of 15 & NRY & N.E. & \multirow[t]{2}{*}{0.89} \\
\hline Yes & 6 out of 31 & NRY & N.E. & \\
\hline \multicolumn{5}{|l|}{ Regression } \\
\hline No & 7 out of 31 & NRY & N.E. & \multirow[t]{2}{*}{0.60} \\
\hline Yes & 2 out of 12 & NRY & N.E. & \\
\hline \multicolumn{5}{|c|}{ Lymphnode involvement } \\
\hline No & 6 out of 21 & NRY & N.E. & \multirow[t]{2}{*}{0.42} \\
\hline Yes & 8 out of 39 & NRY & N.E. & \\
\hline \multicolumn{5}{|l|}{ Stage } \\
\hline$\| B$ & 6 out of 21 & NRY & N.E. & \multirow[t]{2}{*}{0.42} \\
\hline III & 8 out of 39 & NRY & N.E. & \\
\hline
\end{tabular}

melanoma cells are shed only intermittently from the tumours into the circulation; (ii) the lymph nodes work as a filter for tumour cells in the circulation, and (iii) the sensitivity of the RT-PCR is still suboptimal and not all melanoma cell transcripts can be detected (Schittek et al, 1999). Another probable explanation for the three patients who developed recurrent disease despite negative RT-PCR tests is that the recurrent melanoma was tyrosinase negative. Unfortunately tumour specimens from recurrences were not tested for tyrosinase expression.

In conclusion our data suggests that circulating melanoma cells are markers of a high relapse risk and shorter disease-free survival whether detected postoperatively or during follow-up. Tyrosinase mRNA amplification by RT - PCR may be a useful tool for monitoring the efficacy of adjuvant treatment in stage IIB and III melanoma patients.

\section{ACKNOWLEDGEMENTS}

Acknowledgements to the Greek State Scholarships Foundation (IKY).
Chomczynski P, Sacchi N (1987) Single-step method for RNA isolation by acid guanidium thiocianate-phenol-chloroform extraction. Anal Biochem 162: $156-159$

Curry BJ, Myers K, Hersey P (1998) Polymerase chain reaction detection of melanoma cells in the circulation: relation to clinical stage, surgical treatment and recurrence from melanoma. J Clin Oncol 16: 1760-1769

Foss AJ, Guille MJ, Occleston NH, Hykin PG, Hungerford JL, Lightmans S (1995) The detection of melanoma cells in peripheral blood by reverse transcription - polymerase chain reaction. Br J Cancer 72: 155-159 
Glaser R, Rass K, Seiten S, Hauschild A, Christophers E, Tilgen W (1997) Detection of circulating melanoma cells by specific amplification of tyrosinase complementary DNA is not a reliable tumor marker in melanoma patients: A clinical two-center study. J Clin Oncol 15: 2818-2825

Gogas H, Pectasides D, Bafaloukos D, Skarlos D, Aravantinos G, Kalofonos HP, Fountzilas G, Ioannovich J Hellenic Cooperative Oncology Group (HeCOG) (2000) Adjuvant biotherapy with high dose interferon in high-risk melanoma patients (preliminary results). Proc ASCO 19: 575a (abstract 2267)

Jung FA, Buzaid AC, Ross MI, Woods KV, Lee JJ, Albitar M, Grimm EA (1997) Evaluation of tyrosinase mRNA as a tumor marker in the blood of melanoma patients. J Clin Oncol 15: 2826-2831

Kunter U, Buer J, Probst M, Duensing S, Dallmann I, Grosse J, Kirchner H, Schluepen EM, Volkenandt M, Ganser A, Atzpodien J (1996) Peripheral blood tyrosinase messenger RNA detection and survival in malignant melanoma. J Natl Cancer Inst 88: 590-594

Kwon BS, Haq AK, Pomerantz SH, Halaban R (1987) Isolation and sequence of a cDNA clone for human tyrosinase that maps at the mouse c-albino locus. Proc Natl Acad Sci USA 84: 7473 - 7477, (Erratum in Proc Natl Acad Sci USA 1988; 85: 6352)

Mellado B, Gutierrez L, Castel T, Colomer D, Fontanillas M, Castro J, Estapé J (1999) Prognostic significance of the detection of circulating malignant cells by reverse transcriptase - polymerase chain reaction in long term clinically disease-free melanoma patients. Clin Cancer Res 5: 1843-1848

Pialmieri G, Strazzullo M, Ascierto PA, Santriano SMR, Daponte A, Castello G (1999) Polymerase Chain Reaction-based detection of circulating melanoma cells as en effective marker of tumor progression. J Clin Oncol 17: $304-311$

Pittman U, Burchill S, Smith B, Southgate J, Joffe J, Gore M, Selby P (1996) Reverse transcriptase - polymerase chain reaction for expression of tyrosinase to identify malignant melanoma cells in peripheral blood. Ann Oncol 7: $297-301$

Reinhold U, Ludtke Handjery HC, Schnautz S, Kreysel HW, Abken H (1997) The analysis of tyrosinase -specific mRNA in blood samples of melanoma patients by RT - PCR is not a useful test for metastatic tumor progression. J Invest Dermatol 108: 166 - 169

Schittek B, Bodingbauer Y, Ellwanger U, Blaheta HJ, Garbe C (1999) Amplification of Melan A messenger RNA in addition to tyrosinase increase sensitivity of melanoma cell detection in peripheral blood and is associated with the clinical stage and prognosis of malignant melanoma. B J Dermato 141: $30-36$

Smith B, Selby P, Southgate J, Pittman K, Bradley C, Blair GE (1991) Detection of melanoma cells in peripheral blood by means of reverse transcriptase and polymerase chain reaction. Lancet 338: 1227-1229

Stevens GL, Scheer WD, Levine EA (1996) Detection of tyrosinase mRNA from the blood of melanoma patients. Cancer Epidemiol Biomarkers Prev 5: $293-296$ 